Supplementary Information

\title{
Revisiting Thin-Layer Electrochemistry in a Chip-Type Cell for the Study of Electroorganic Reactions
}

\author{
Samuel J. Shin, ${ }^{\ddagger 1}$ Ji Yong Kim, ${ }^{\ddagger 1}$ Sohee An, ${ }^{1}$ Moonjoo Kim, ${ }^{1}$ Minjee Seo,${ }^{2}$ Su Yong Go, ${ }^{1}$ \\ Hyunho Chung, ${ }^{1}$ MinKeun Lee, ${ }^{1}$ Min-Gyeong Kim, ${ }^{3}$ Hong Geun Lee, ${ }^{1}$ Taek Dong Chung*1,4 \\ ${ }^{1}$ Department of Chemistry, Seoul National University, Seoul, 08826, Republic of Korea \\ ${ }^{2}$ Department of Chemistry Education, Korea National University of Education, Cheongju-si, Chungbuk 28173, \\ Republic of Korea \\ ${ }^{3}$ Department of Chemistry Education, Seoul National University, Seoul, 08826, Republic of Korea \\ ${ }^{4}$ Advanced Institutes of Convergence Technology, Suwon-si, Gyeonggi-do, 16229, Republic of Korea \\ $\$$ These authors contributed equally. \\ *Corresponding author: tdchung@snu.ac.kr
}




\section{General Procedure for Chemical Characterization}

Nuclear magnetic resonance (NMR) spectra were recorded in DMSO on Varian 400 NMR $(400 \mathrm{MHz})$ spectrometers, and the residual solvent signal was used as a reference. ${ }^{19} \mathrm{~F}$ NMR chemical shifts were referenced to external $\mathrm{C}_{6} \mathrm{H}_{5} \mathrm{CF}_{3}$ (-63.72 ppm). High-resolution mass spectrometry (HRMS) was performed using the electrospray ionization (ESI) method. Chemical shifts are reported in ppm and coupling constants are given in $\mathrm{Hz}$. Reactions were monitored by thin-layer chromatography (TLC) on EMD Silica Gel 60 F254 plates, and visualized either using UV light ( $254 \mathrm{~nm}$ ) or by staining with potassium permanganate and heating. The ${ }^{13} \mathrm{C}$ signal of the carbon bonded to boron was not observed in all cases because of quadrupolar relaxation.

\section{Preparation of alkyltrifluoroborate salt}<smiles>[M]C(B1OC(C)(C)C(C)(C)O1)c1ccc(OC)cc1</smiles>

1 aq. $\mathrm{KHF}_{2}(5.5$ equiv, $4.5 \mathrm{M})$

$\mathrm{MeOH}(0.4 \mathrm{M}), \mathrm{rt}, 10 \mathrm{~h}$<smiles>COc1ccc(C(C)(C)Br)cc1</smiles>

2

The alkyltrifluoroborate salt of (4-MeOPh) $\mathrm{CHCH}_{3} \mathrm{BF}_{3} \mathrm{~K} 2$ was synthesized as follows. Alkyl pinacol boronic ester 1 was prepared via a previously reported procedure. ${ }^{1,2}$ To a stirred solution of potassium hydrogen difluoride ( $40.7 \mathrm{mmol})$ in $\mathrm{H}_{2} \mathrm{O}(9 \mathrm{~mL}$ ) at room temperature, a solution of alkyl pinacol boronic ester 1 (7.4 mmol) in $\mathrm{MeOH}$ $(18.5 \mathrm{~mL})$ was added dropwise. The reaction mixture was then stirred at the same temperature for $10 \mathrm{~h}$. After 10 $\mathrm{h}$, the resulting suspension was concentrated under reduced pressure. $\mathrm{H}_{2} \mathrm{O}$ was azeotropically removed by suspension in toluene followed by rotary evaporation. The resultant solid was resuspended in hot acetone and filtered. The filtrate was then concentrated to minimal volume, and the alkyltrifluoroborate $\mathbf{2}$ was precipitated by the addition of cold hexanes. The mixture was filtered, washed with cold hexanes, and then dried on high vacuum overnight to yield the desired alkyltrifluoroborate $2(912.6 \mathrm{mg}, 3.77 \mathrm{mmol}, 51 \%$ yield $)$ as a white solid. 
(a)

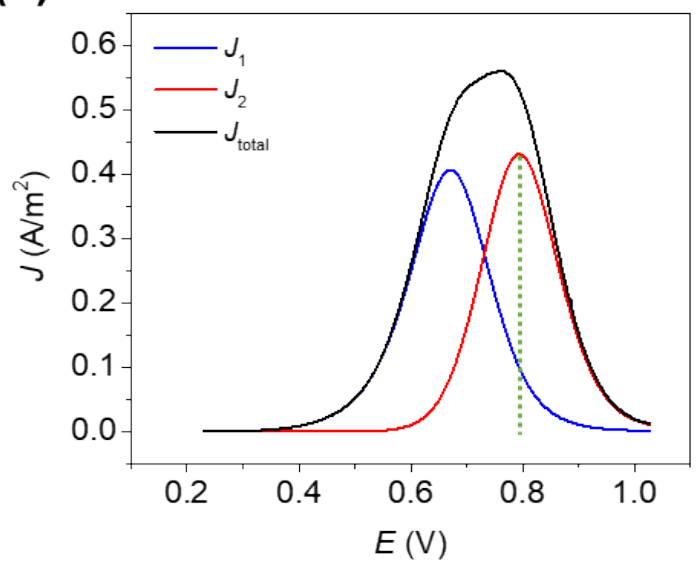

(b)

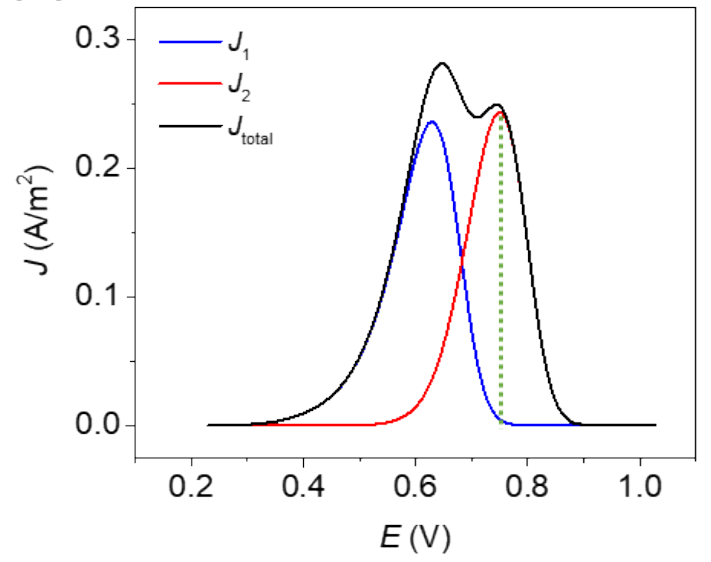

Figure S1. Simulated SWVs plotting the current density from the first (blue) or second (red) oxidation reaction separately. (a) Semi-infinite diffusion and (b) thin-layer of $20 \mu \mathrm{m} . E_{1}{ }^{0}=0.5 \mathrm{~V}$ and $E_{2}{ }^{0}=0.6 \mathrm{~V}$. The smaller overlap of $J_{1}$ and $J_{2}$ in the thin-layer cell is represented by the depleted $J_{1}$ at the $E_{\mathrm{p}, 2}$ (green dotted line). 

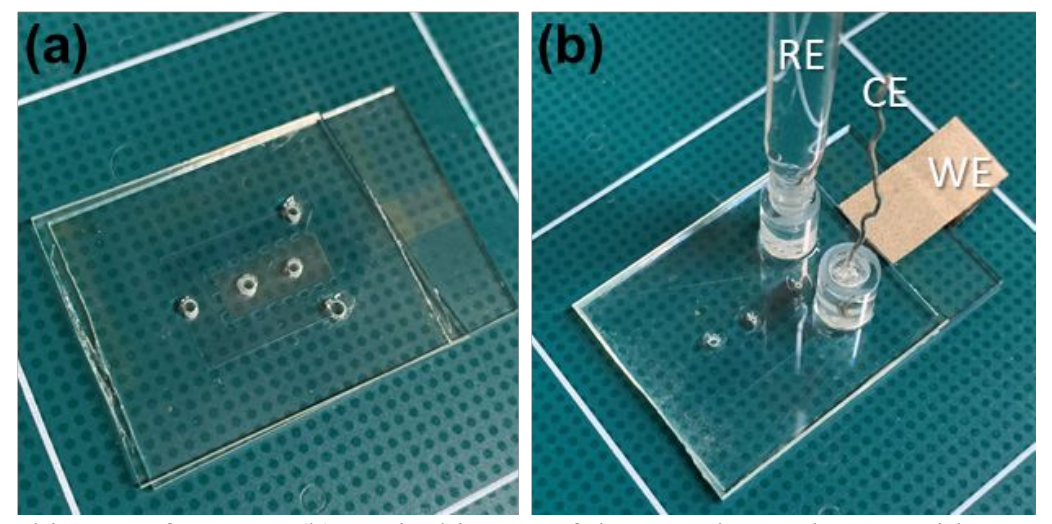

Figure S2. (a) Optical image of TEAM. (b) Optical image of the experimental setup with TEAM. 

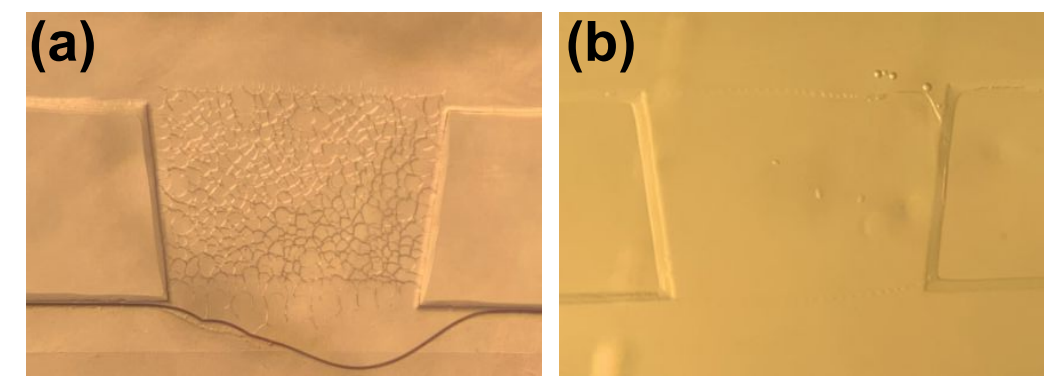

Figure S3. (a) pDADMAC polyelectrolyte gel in DCM solution. (b) pLA-TFPB polyelectrolyte gel in DCM solution. 
Table S1. $\Delta E_{\mathrm{p}}$ at different scan rates in CVs shown in Figure 2a.

\begin{tabular}{|c|c|c|c|c|}
\hline Scan rate $(\mathrm{mV} / \mathrm{s})$ & 10 & 5 & 2 & 1 \\
\hline$\Delta E_{\mathrm{p}}(\mathrm{mV})$ & 19 & 10 & 10 & 6 \\
\hline$\Delta E_{\mathrm{p}}, i \mathrm{R}$ compensated $(\mathrm{mV})$ & 16.2 & 8.5 & 6.4 & 5.7 \\
\hline
\end{tabular}




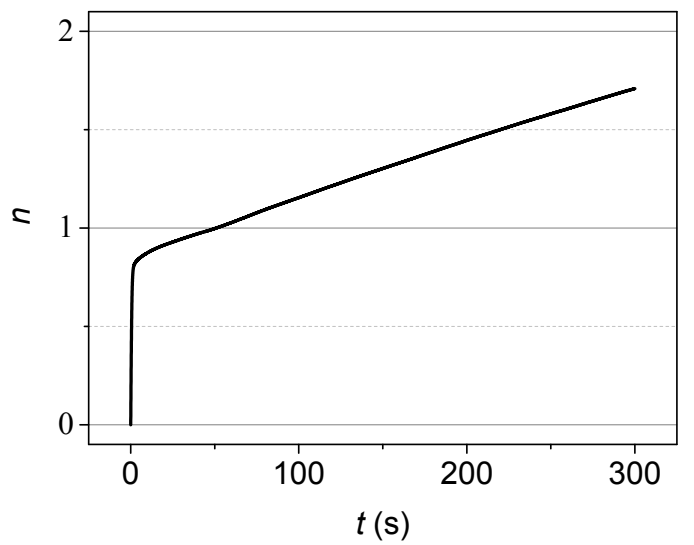

Figure S4. The $n-t$ plot of $1 \mathrm{mM}$ ferrocyanide in $1 \mathrm{M} \mathrm{KCl}$ using TEAM without polyelectrolyte gel. 


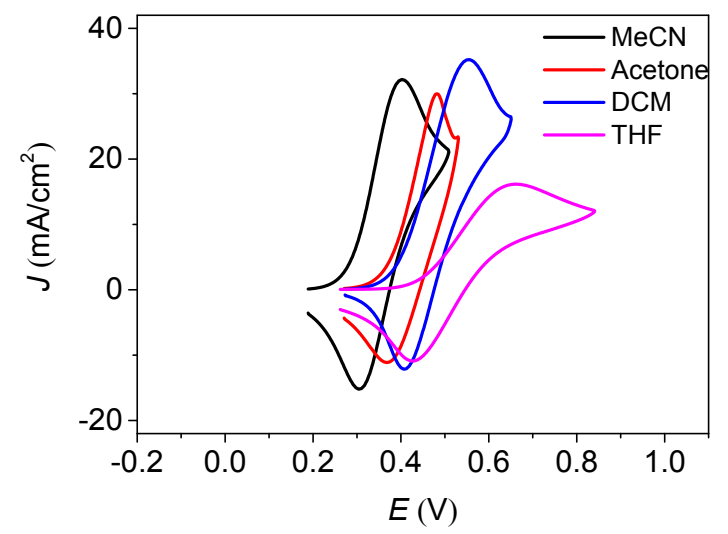

Figure S5. CVs of $1 \mathrm{mM} \mathrm{Fc}$ at semi-infinite diffusion condition of ITO electrode in different organic solvents in $\mathrm{MeCN}$, acetone, DCM, and THF with $0.1 \mathrm{M} \mathrm{TBAPF}_{6}$ electrolyte $(10 \mathrm{mV} / \mathrm{s})$. 


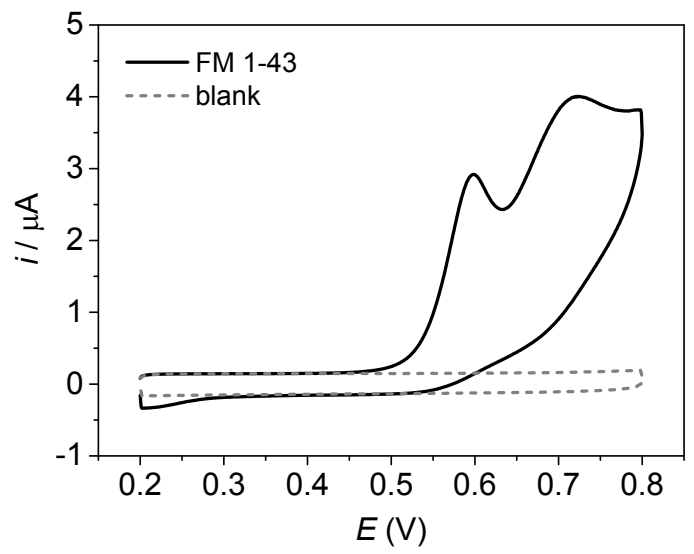

Figure S6. CVs of $50 \mu \mathrm{M}$ FM 1-43 in $0.1 \mathrm{M} \mathrm{KCl}$ (solid line) and background current of $0.1 \mathrm{M} \mathrm{KCl}$ (dashed line) recorded in ITO electrode with semi-infinite diffusion at the scan rate of $50 \mathrm{mV} / \mathrm{s}$. 
Scheme S1. Schematic illustration of the experimental configuration to study in situ UV-Vis spectroelectrochemistry using TEAM.

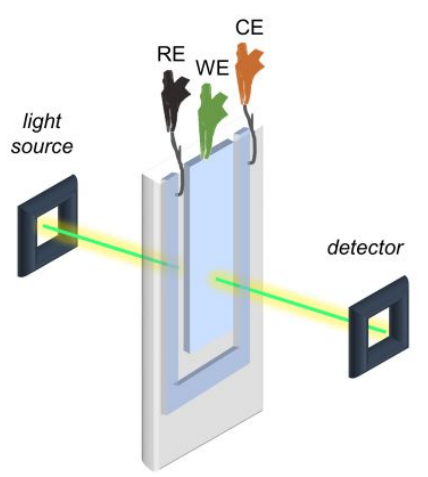


(a)

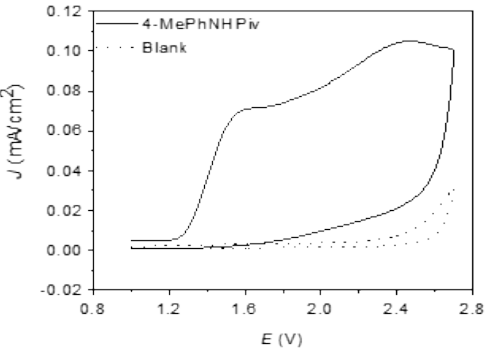

(b)

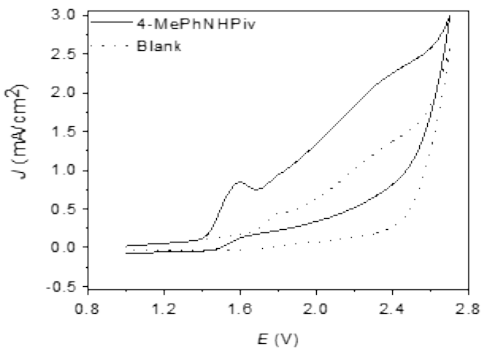

(c)

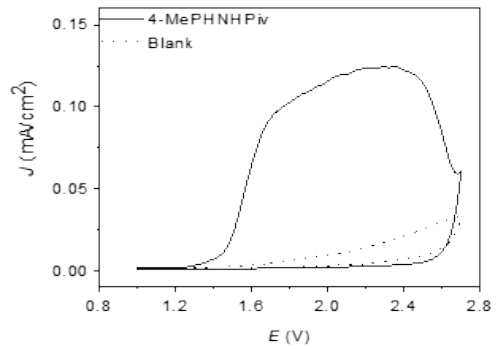

Figure S7. CVs in semi-infinite diffusion condition of $1 \mathrm{mM}$ 4-MePhNHPiv in $0.1 \mathrm{M}$ TBAP (a) in HFIP at ITO electrode $(10 \mathrm{mV} / \mathrm{s}),(b)$ in DCM at glassy carbon $(200 \mathrm{mV} / \mathrm{s})$, and (c) in DCM at ITO $(10 \mathrm{mV} / \mathrm{s})$. The scan rate of the (b) was adjusted for comparison to the literature of the CV in HFIP. ${ }^{1}$

The overall voltammetric characteristics of anilide do not significantly differ in while peak potentials and their separation, $\Delta E$, vary with electrode material. 
(a)

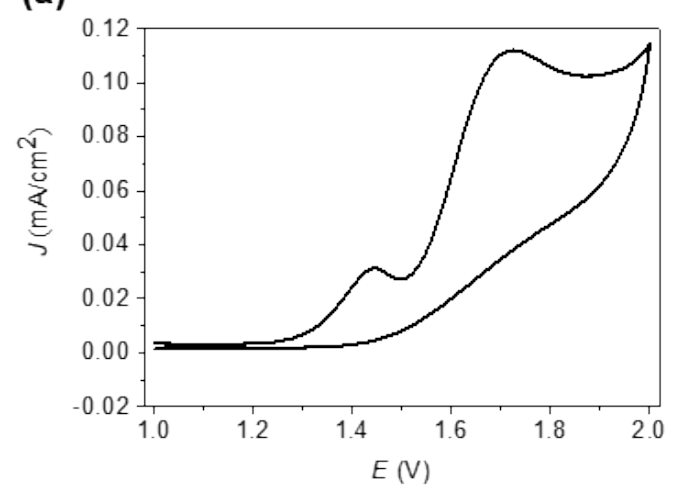

(b)

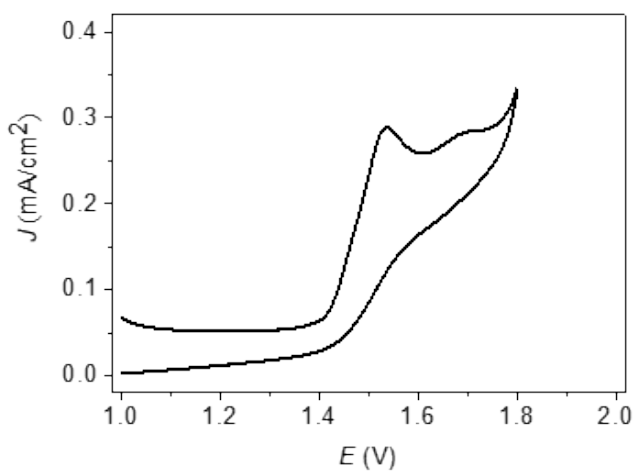

Figure S8. CVs $(10 \mathrm{mV} / \mathrm{s})$ in semi-infinite diffusion condition of $1 \mathrm{mM}(4-\mathrm{MeOPh}) \mathrm{CHCH}_{3} \mathrm{BF}_{3} \mathrm{~K}$ in $0.1 \mathrm{M}$ $\mathrm{TBAPF}_{6}$ of MeCN solution in air on (a) ITO and (b) glassy carbon electrode. 
Table S2. Summary of the compounds and their oxidation potentials and $\boldsymbol{n}$ measured by TEAM in this work.

\begin{tabular}{|c|c|c|c|c|}
\hline Compound & Solvent & $E(\mathbf{V}) *$ & $E_{\text {app }}(\mathrm{V})$ & $n$ \\
\hline$\left[\mathrm{Fe}(\mathrm{CN})_{6}\right]^{4-}$ & $\mathrm{H}_{2} \mathrm{O}$ & $0.26^{\mathrm{a}}$ & 0.4 & $0.98 \pm 5.1 \%$ \\
\hline$o$-tolidine & $\mathrm{H}_{2} \mathrm{O}$ & $0.54^{\mathrm{a}}$ & 0.7 & $1.98 \pm 0.3 \%$ \\
\hline \multirow{4}{*}{$\mathrm{Fc}$} & $\mathrm{MeCN}$ & $0.36^{\mathrm{a}}$ & 0.5 & $1.01 \pm 2.8 \%$ \\
\hline & Acetone & $0.43^{\mathrm{a}}$ & 0.5 & $1.01 \pm 4.6 \%$ \\
\hline & $\mathrm{DCM}$ & $0.40^{\mathrm{a}}$ & 0.7 & $1.01 \pm 3.7 \%$ \\
\hline & THF & $0.45^{\mathrm{a}}$ & 0.7 & $1.00 \pm 4.5 \%$ \\
\hline FM 1-43 & $\mathrm{H}_{2} \mathrm{O}$ & $0.54^{\mathrm{b}}$ & 0.5 & $1.01 \pm 11.9 \%$ \\
\hline \multirow[t]{2}{*}{ 4-MePhNHPiv } & HFIP & $\begin{array}{l}1.74^{\mathrm{b}} \\
2.31^{\mathrm{b}}\end{array}$ & $\begin{array}{l}1.8 \\
2.5\end{array}$ & $\begin{array}{c}1.00 \pm 6.6 \% \\
1.98 \pm 6.8 \%\end{array}$ \\
\hline & DCM & $2.14^{\mathrm{b}}$ & 1.8 & $2.02 \pm 9.3 \%$ \\
\hline 4-MeOPhNHPiv & HFIP & $1.95^{\mathrm{b}}$ & 1.8 & $1.95 \pm 5.1 \%$ \\
\hline (4-MeO) $\mathrm{PhCHCH}_{3} \mathrm{BF}_{3} \mathrm{~K}$ & $\mathrm{MeCN}$ & $\begin{array}{l}1.34^{\mathrm{b}} \\
1.86^{\mathrm{b}}\end{array}$ & $\begin{array}{l}1.4 \\
1.8\end{array}$ & $\begin{array}{r}1.00 \pm 4.8 \% \\
1.96 \pm 4.1 \%\end{array}$ \\
\hline
\end{tabular}

${ }^{* a} E_{1 / 2},{ }^{\mathrm{b}} E_{\mathrm{p}},(\mathrm{V}$ vs. $\mathrm{Ag} / \mathrm{AgCl}$ in $3 \mathrm{M} \mathrm{NaCl})$ 


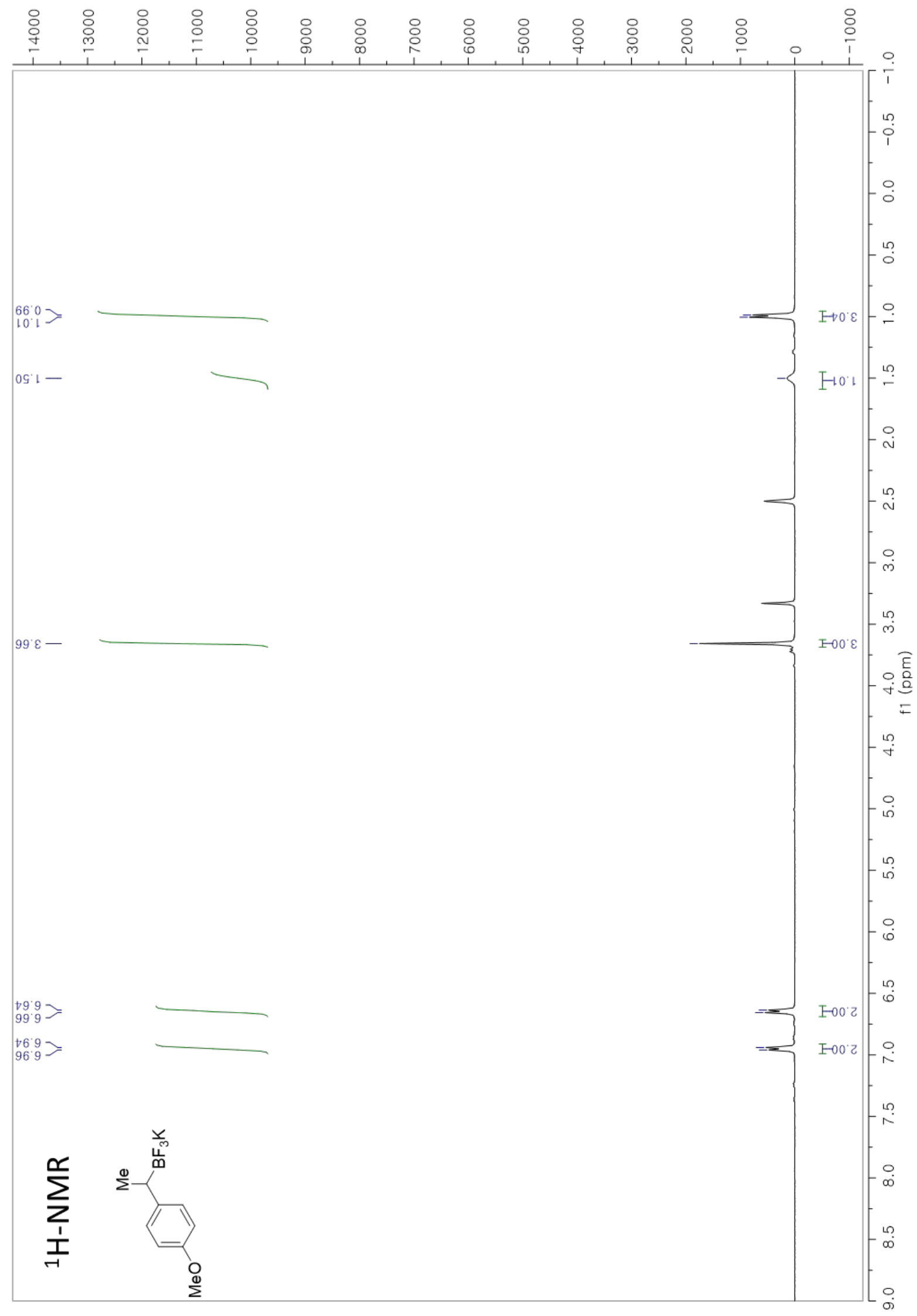




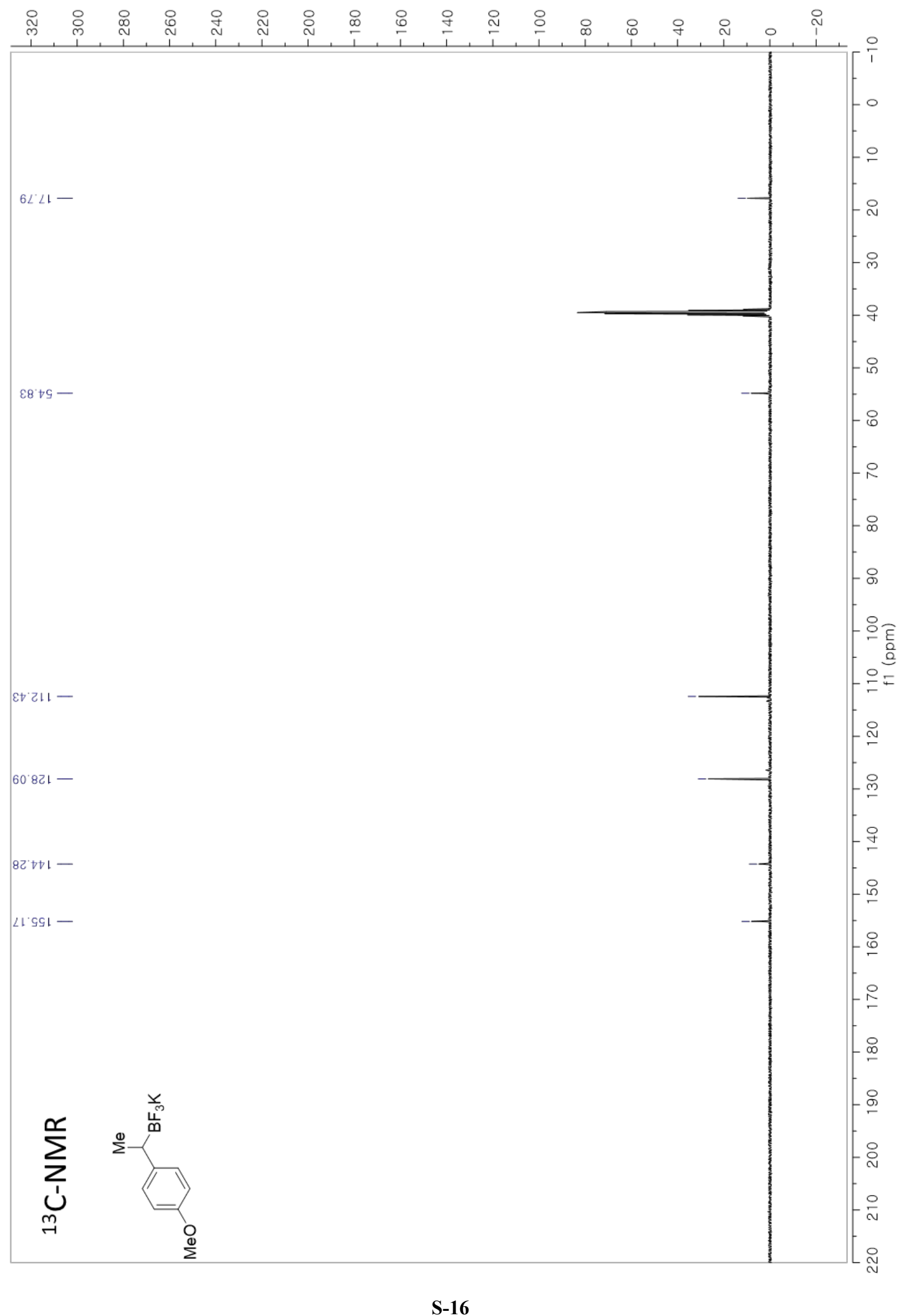




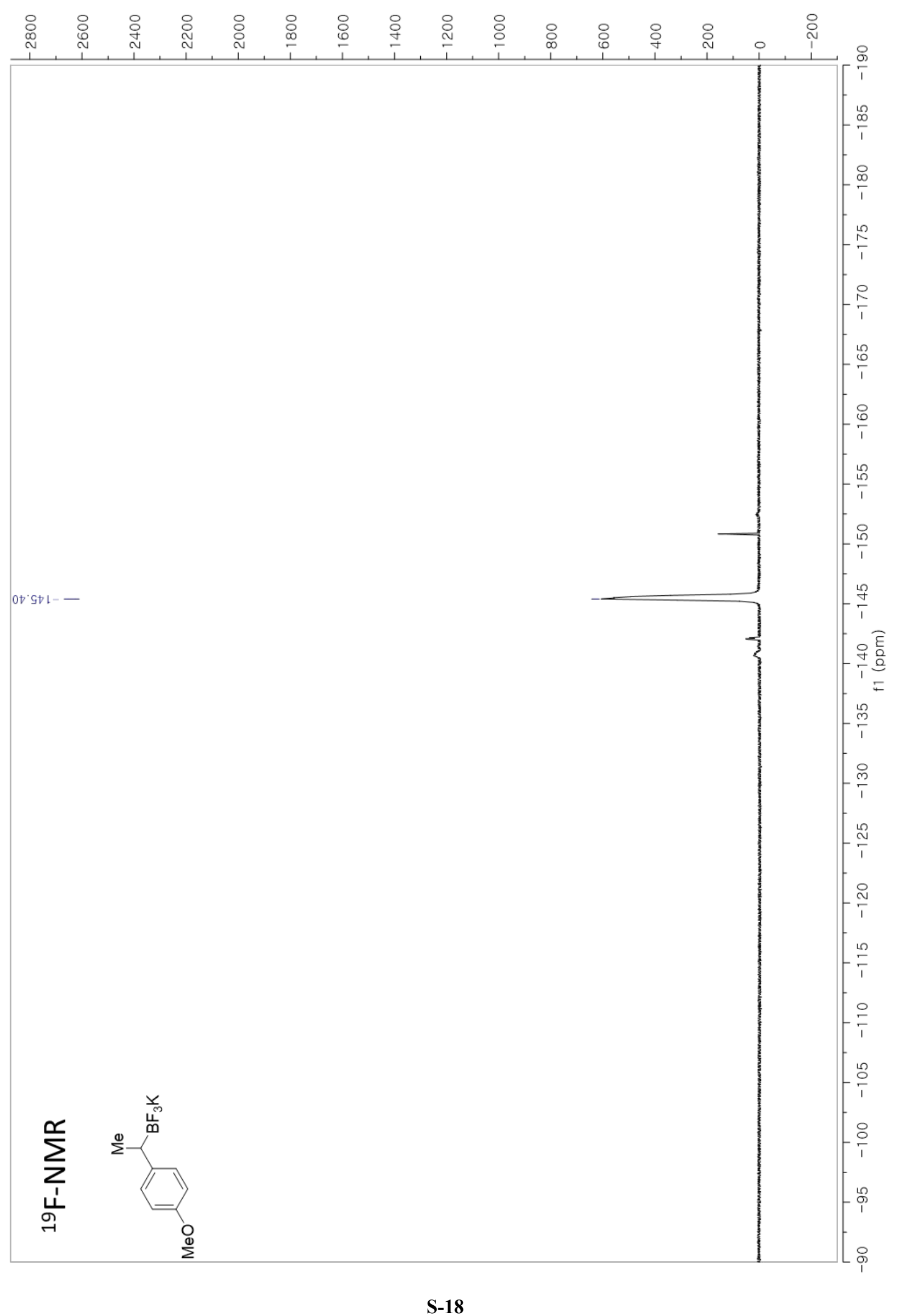




\section{References}

(1) Hashimoto, T.; Ishimaru, T.; Shiota, K.; Yamaguchi, Y. Bottleable $\mathrm{NiCl}_{2}$ (Dppe) as a Catalyst for the Markovnikov-Selective Hydroboration of Styrenes with Bis(Pinacolato)Diboron. Chem. Commun. 2020, 56 (78), 11701-11704. https://doi.org/10.1039/d0cc05246a.

(2) Go, S. Y.; Chung, H.; Shin, S. J.; Ahn, S.; Youn, J. H.; Im, T. Y.; Kim, J. Y.; Chung, T. D.; Lee, H. G. A Unified Synthetic Strategy to Introduce Heteroatoms via Electrochemical Functionalization of Alkyl Organoboron Reagents. ChemRxiv 2021. https://doi.org/10.33774/chemrxiv-2021-bvf11. 